\title{
PENGARUH FREE CASH FLOW DAN FINANCIAL LEVERAGE TERHADAP EARNING MANAGEMENT DENGAN GOOD CORPORATE GOVERNANCE SEBAGAI VARIABEL MODERASI
}

\section{Tjindrawati Kosasih, Melvie Paramitha}

Fakultas Ekonomi, Universitas Widya Kartika, Indonesia

Email: tjindrak14@gmail.com, melvieparamithauwika@gmail.com

\begin{abstract}
Earning Management is one of the various efforts that can be made by companies in engineering the numbers in the financial statements so that the company's financial statements can be seen in good condition for investors and other readers. This study aims to determine the effect of free cash flow and financial leverage on earnings management with good corporate governance as a moderating variable in transportation service companies. This study uses data from 26 transportation service companies from 2017-2019 that have been listed on the Indonesia Stock Exchange. The data analysis technique used in this study is the Partial Least Square (PLS) analysis method where PLS analysis is an analytical method that is not based on many assumptions or conditions and can handle many variables at once even though there is multicollinearity in these variables. The results show that free cash flow and financial leverage have no effect on earning management and good corporate governance cannot moderate the relationship between free cash flow and financial leverage on earning management.
\end{abstract}

Keywords: Free Cash Flow, Financial Leverage, Earning Management, Good Corporate Governance

\begin{abstract}
Abstrak
Earning Management merupakan salah satu dari berbagai upaya yang dapat dilakukan oleh perusahaan dalam merekayasa angka-angka dalam laporan keuangan sehingga laporan keuangan perusahaan dapat terlihat kondisi baik bagi investor dan pembaca lainnya. Penelitian ini bertujuan untuk mengetahui pengaruh free cash flow dan financial leverage terhadap earning management dengan good corporate governance sebagai variabel moderasi pada perusahaan jasa transportasi. Penelitian ini menggunakan data dari 26 perusahaan jasa transportasi dari tahun 2017-2019 yang telah terdaftar di Bursa Efek Indonesia. Teknik analisis data yang digunakan dalam penelitian ini adalah metode analisis Partial Least Square (PLS) dimana analisis PLS merupakan suatu metode analisis yang tidak didasarkan pada banyak asumsi atau syarat serta dapat menangani banyak variabel sekaligus sekalipun terdapat multikolineritas dalam variabel-variabel tersebut. Hasil menunjukan bahwa free cash flow dan financial leverage tidak berpengaruh terhadap earning management serta good corporate
\end{abstract}


governance tidak dapat memoderasi hubungan antara free cash flow dan financial leverage terhadap earning management.

Kata kunci: Free Cash Flow, Financial Leverage, Earning Management, Good Corporate Governance

Diterima: 25-10-2021Ｄirevisi: 13-11-2021 Diterbitkan: 20-11-2021

\section{Pendahuluan}

Semakin berkembangnya era globalisasi maka semakin bertambah dan berkembang pula perusahaan yang ada di dunia salah satunya Indonesia. Setiap perusahaan memiliki yang dinamakan Laporan Keuangan baik secara bulanan atau tahunan. Menurut Fahmi, Laporan Keuangan merupakan suatu informasi yang menggambarkan kondisi keuangan suatu perusahaan dan lebih jauh informasi tersebut dapat dijadikan sebagai gambaran kinerja keuangan perusahaan tersebut (Fahmi, 2011). Laporan keuangan setiap perusahaan akan berisikan mengenai informasi-informasi yang berkaitan dengan bagaimana posisi keuangan sebuah perusahaan, bagaimana kinerja sebuah perusahaan, dan bagaimana perubahan posisi keuangan dalam satu periode. Umumnya Laporan Keuangan yang dipublikasikan oleh perusahaan disusun menggunakan Standar Akuntansi Keuangan (SAK). Dengan adanya standar ini pembuat laporan keuangan memiliki kebebasan dalam menentukan metode kebijakan akuntansi yang ingin digunakan yang dapat menimbulkan Earning Management ataupun melakukan aktivitas yang dapat menimbulkan laba (Yunila \& Aryati, 2018). Earning Management biasanya dilakukan oleh perusahaan dengan tujuan untuk membuat seakan kondisi keuangan perusahaan dalam kondisi bagus. Hal ini berakibat kepada laporan keuangan perusahaan yang diberikan kepada pihak ketiga misalnya investor, calon investor, Bank, bahkan ketika melaporkan laporan keuangannya ke Bursa Efek Indonesia (BEI). Dimana Sulistyanto mengatakan praktik Earning Management merupakan perilaku oportunistik seorang manajer untuk memaksimalkan kesejahteraan dan kepentingan pribadi (Sulistyanto, 2008).

Penelitian Agustia menyatakan bahwa Leverage Ratio berpengaruh terhadap Earning Management, dimana bila perusahaan memiliki Leverage yang tinggi berarti proporsi hutangnya lebih tinggi dibandingkan dengan aktivitasnya maka perusahaan cenderung melakukan Earning Management (Agustia, 2013). Disisi lain terdapat penelitian yang menemukan hasil berbeda dimana, Setiawan menemukan bahwa Leverage tidak berpengaruh terhadap Earning Management sehingga semakin besar atau semakin kecilnya Leverage tidak dapat menjadikan alasan suatu perusahaan untuk melakukan Earning Management (Setiawan, 2019).

Menurut Setiawati perusahaan dengan Free Cash Flow yang tinggi akan memiliki kesempatan yang lebih besar untuk bertahan dalam situasi yang buruk karena perusahaan masih memiliki kesempatan untuk melakukan investasi dan belanja untuk mempertahankan operasi yang berjalan (Setiawati, Mujiyati, \& Rosit, 2019). Namun Herlambang menemukan bahwa Free Cash Flow berpengaruh negatif dan tidak 
signifikan terhadap Earning Management, dijelaskan bahwa bila suatu perusahaan memiliki Free Cash Flow yang besar maka tidak akan membuat manajer untuk melakukan kecurangan Earning Management (Herlambang, Halim, \& Haryetti, 2017).

Dalam penelitian Nugroho ditemukan beberapa hasil dimana dalam penelitian tersebut menggunakan beberapa komponen Good Corporate Governance yaitu kepemilikan manajerial, kepemilikan institusional, ukuran perusahaan, dan dewan komisaris independen (Nugroho, 2020). Hasil dari penelitian Nugroho mengatakan bahwa ukuran perusahaan berpengaruh terhadap Earning Management, sedangkan kepemilikan manajerial, kepemilikan institusional, serta dewan komisaris independen tidak berpengaruh terhadap Earning Management. Dalam penelitian ini Good Corporate Governance yang akan digunakan merupakan indeks CG yang mengambil kriteria dari BAPEPAM. Penelitian ini didasarkan atas fenomena yang telah terjadi pada tahun 2019, dimana Garuda Indonesia berhasil membukukan laba untuk tahun buku 2018 yang berbanding terbalik dengan tahun buku 2017 dimana pada saat itu Garuda Indonesia mengalami kerugian besar.

\section{Tinjauan Literatur \\ Teori Keagenan}

Fathoni mengatakan bahwa Teori Keagenan atau Agency Theory dikemukakan oleh Jensen dan Meckling pada tahun 1976 yang menyatakan bahwa hubungan keagenan adalah sebuah kontrak antara agen dan prinsipal. Yang dimaksud dengan agen adalah pihak yang mengelola perusahaan atau pihak manajemen, sedangkan prinsipal adalah pemilik perusahaan atau para pemegang saham (Widyaningrum, Amboningtyas, \& Fathoni, 2018). Di dalam teori keagenan menjelaskan adanya hubungan keagenan (Agency Relationship). Teori ini mengasumsikan bahwa masing-masing pihak baik pihak agen maupun pihak prinsipal sama-sama termotivasi untuk menaikan harga untuk masing-masing kepentingan. Adanya kepentingan yang berbeda antara kedua pihak yang menyebabkan muncul permasalahan keagenan (Agency Problems).

\section{Earning Management}

Menurut Sulistyanto, Earning Management adalah upaya untuk merekayasa angkaangka dalam laporan keuangan dengan mempermainkan metode dan prosedur akuntansi yang digunakan perusahaan. Sulistyanto mengelompokkan dalam tiga kelompok model empiris Manajemen Laba yang diklasifikasikan atas dasar basis pengukuran yang digunakan yaitu model yang berbasis akrual agregat (Aggregate Accruals), akrual khusus (Specific Accruals) dan distribusi laba (Distribution Of Earnings) (Sulistyanto, 2008).

\section{Free Cash Flow}

Menurut Ross et al. (2000) mendefinisikan bahwa Free Cash Flow merupakan kas perusahaan yang dapat didistribusikan kepada kreditor atau pemegang saham yang tidak diperlukan untuk modal kerja atau investasi pada asset (Herlambang, 2017). Menurut Ross kas tersebut biasanya menimbulkan konflik kepentingan antara manajer dan pemegang saham. Manajer lebih menginginkan dana tersebut diinvestasi lagi pada proyek-proyek yang dapat menghasilkan keuntungan, karena alternatif ini akan 
meningkatkan insentif yang diterimanya. Di sisi lain, pemegang saham mengharapkan sisa dana tersebut dibagikan sehingga akan menambah kesejahteraan mereka. menyatakan bahwa "tidak ada yang salah dengan arus kas bebas negatif sepanjang ia berasal dari perkembangan yang menguntungkan". Brigham dan Houston menjabarkan jika suatu perusahaan memiliki nilai free cash flow yang negatif dikarenakan NOPAT yang negatif, maka perusahaan dalam kondisi buruk dan sedang dalam terdapat masalah operasi. Namun, tidak menutup kemungkinan suatu perusahaan yang memiliki tingkat pertumbuhan yang tinggi serta NOPAT yang positif namun memiliki free cash flow yang negatif (Brigham dan Houston 2010).

\section{Financial Leverage}

Dalam (Herlambang et al., 2017), Martono dan Harjito mengatakan bahwa Financial Leverage merupakan penggunaan dana dengan beban tetap dengan harapan atas penggunaan dana tersebut akan memperbesar pendapatan per-lembar saham. Sedangkan menurut Financial Leverage dapat diartikan sebagai daya ungkit dari biaya tetap operasi dan beban tetap finansial dengan menggunakan modal asing untuk peningkatan keuntungan (Irfani, 2020). Menurut Sudana Financial Leverage terjadi karena perusahaan melakukan suatu transaksi dengan dana yang mengakibatkan adanya beban tetap, dalam hal ini dana dapat dicontohkan sebagai hutang dan beban tetap sebagai bunga. Sudana juga membagi Financial Leverage menjadi dua yaitu financial structure (struktur keuangan) dan capital structure (struktur modal).

\section{Good Corporate Governance}

Sulistyanto mengatakan Good Corporate Governance secara definitif dapat diartikan sebagai sebuah sistem mengatur dan mengendalikan sebuah perusahaan agar perusahaan tersebut dapat menciptakan nilai tambah bagi semua pemangku kepentingan atau stakeholder. Pedoman Umum Good Corporate Governance Indonesia (2006) menyatakan bahwa Good Corporate Governance mencakup 5 asas, yaitu: Transparansi, Akuntabilitas, Responsibilitas, Independensi, dan Kewajaran serta kesetaraan. Kelima asas tersebut pelaksanaannya mendukung tersedianya informasi secara jelas, akurat, memadai, tepat waktu, dan dapat diperbandingkan serta mudah diakses (Sulistyanto, 2008).

\section{Hubungan Free Cash Flow Terhadap Earning Management}

Free Cash Flow dalam perusahaan dapat menjadi sebuah tanda bagi perusahaan maupun para investor. Perusahaan dengan Free Cash Flow besar menandakan kinerja perusahaan tersebut dalam keadaan baik, sebaliknya bila Free Cash Flow rendah menandakan bahwa kinerja perusahaan tersebut tidak dalam keadaan baik. Free Cash Flow juga dapat menjadi dampak meningkatnya praktik Earning Management. Hal ini dapat terjadi bila Free Cash Flow perusahaan tinggi dan tidak mendapat pengawasan yang memadai sehingga pihak manajer menggunakannya untuk investasi yang dapat menguntungkan dirinya sendiri. Earning Management dapat dilakukan agar ketidak seimbangan dalam penggunaan Free Cash Flow dapat tertutupi (Bukit dan Iskandar, 2009 dalam Kodriyah dan Fitri, 2017). Berdasarkan uraian tersebut, hipotesis yang dapat 
dirumuskan adalah sebagai berikut: $\mathrm{H}_{1}$ : Free Cash Flow berpengaruh terhadap Earning Management

\section{Hubungan Financial Leverage Terhadap Earning Management}

Leverage digunakan oleh perusahaan untuk mengukur aset perusahaan yang didapat dari hutang. Menurut Kasmir dalam (Setiawan, 2019) Rasio Leverage digunakan oleh perusahaan untuk mengukur kemampuan perusahaan dalam membayar kewajibannya, baik jangka pendek maupun jangka panjang. Dapat dikatakan bahwa perusahaan ingin melakukan Earning Management dikarenakan mereka ingin memperlihatkan bahwa hutang yang mereka miliki setara dengan kewajiban membayar hutang mereka. Berdasarkan uraian tersebut, hipotesis yang dapat dirumuskan adalah sebagai berikut:

$\mathrm{H}_{2}$ : Financial Leverage berpengaruh terhadap Earning Management

\section{Metode Penelitian}

\section{Kerangka Konseptual}

Berdasarkan hipotesis yang telah rumuskan, berikut adalah kerangka konseptual dalam penelitian ini:

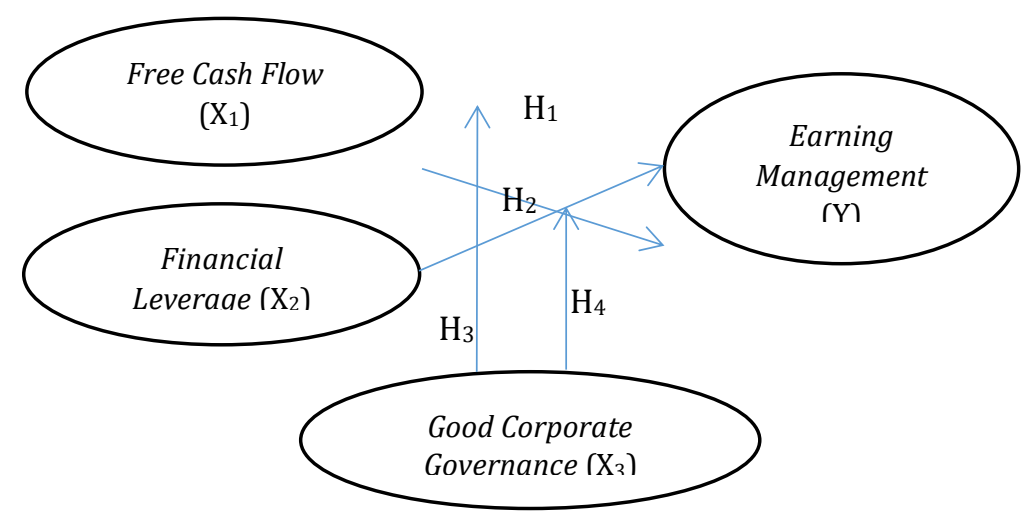

\section{Definisi Operasional Variabel}

1. Free Cash Flow

Free Cash Flow sebagai kas bebas yang tidak digunakan akan perusahaan alihkan kepada kreditur atau pemegang saham. Free Cash Flow dapat diukur dengan rumus sebagai berikut yaitu:

Free Cash Flow = NOPAT - Investasi Bersih pada Modal Operasi

2. Financial Leverage

Leverage merupakan sebuah tanda bagi perusahaan yang berisikan sumber dana operasi yang digunakan serta resiko yang dihadapi perusahaan. Bila resiko perusahaan semakin besar maka kesulitan dalam menghasilkan laba untuk kedepannya akan semakin besar pula. Rumus yang digunakan dalam penelitian ini adalah: 


$$
\text { Leverage }=\frac{\text { TotalDebt } / \text { Liabilitas }}{\text { TotalAsset }}
$$

\section{Earning Management}

Earning Management merupakan sebuah tindakan yang dilakukan oleh perusahaan untuk memperbaiki laporan keuangan yang akan dilaporkan sehingga terlihat bahwa kinerja perusahaan sedang bagus. Dalam hal ini manajer dapat menaikkan (menurunkan) laba yang dilaporkan dalam unitnya namun tidak mempengaruhi profitabilitas dalam jangka panjang. Dalam penelitian ini rumus yang digunakan dalam penelitian ini adalah:

$$
\begin{gathered}
\qquad \mathrm{TAC}_{\mathrm{it}}=\mathrm{N}_{\mathrm{it}}-\mathrm{CFO}_{\mathrm{it}} \\
\mathrm{TAC} \mathrm{C}_{\mathrm{it}} / \mathrm{A}_{\mathrm{it}-1}=\beta_{1}\left(1 / \mathrm{A}_{\mathrm{it}-1}\right)+\beta_{2}\left(\Delta \mathrm{REV}_{\mathrm{t}} / \mathrm{A}_{\mathrm{it}-1}\right)+\beta_{3}\left(\mathrm{PPE}_{\mathrm{t}} / \mathrm{A}_{\mathrm{it}-1}\right)+\mathrm{e} \\
\mathrm{NDA}_{\mathrm{it}}=\beta_{1}\left(1 / \mathrm{A}_{\mathrm{it}-1}\right)+\beta_{2}\left(\Delta \mathrm{REV}_{\mathrm{t}} / \mathrm{A}_{\mathrm{it}-1}-\Delta \mathrm{REC}_{\mathrm{t}} / \mathrm{A}_{\mathrm{it}-1}\right)+\beta_{3}\left(\mathrm{PPE}_{\mathrm{t}} / \mathrm{A}_{\mathrm{it}-1}\right) \\
\mathrm{DA} \mathrm{A}_{\mathrm{it}}=\mathrm{TA}_{\mathrm{it}} / \mathrm{A}_{\mathrm{it}-1}-\mathrm{NDA} \mathrm{A}_{\mathrm{it}}
\end{gathered}
$$

\section{Good Corporate Governance}

Dalam penelitian ini Good Corporate Governance merupakan variabel moderasi dimana variabel ini menggambarkan sebuah sistem yang dilakukan perusahaan agar meminimalkan terjadinya Earning Management. Good Corporate Governance dalam penelitian ini dihitung dengan menggunakan metode indeks governance dengan menggunakan rumus:

$$
\text { Ipcg }=\frac{\text { JumlahSkor Item PengungkapanCG }}{\text { Skor Maksimum Item Pengungkapan CG }} \times 100 \%
$$

\section{Populasi dan Sampel}

Populasi dalam penelitian ini adalah Perusahaan Jasa Transportasi yang terdaftar di Bursa Efek Indonesia tahun 2017-2019. Dari populasi tersebut, peneliti memiliki sampel yang akan digunakan untuk tujuan penelitian. Metode pengumpulan sampel yang digunakan peneliti adalah purposive sampling, dimana peneliti menentukan sampel yang akan digunakan berdasarkan pertimbangan tertentu untuk tujuan penelitian. Berdasarkan data populasi yang didapat, terdapat 47 perusahaan jasa transportasi yang tercatat di Bursa Efek Indonesia yang akan disaring menjadi sampel sesuai dengan tujuan penelitian. Kriteria yang digunakan peneliti untuk memilih sampel adalah sebagai berikut:

1. Perusahaan Jasa Transportasi yang tercatat di Bursa Efek Indonesia.

2. Perusahaan yang melaporkan laporan keuangannya secara berturut-turut selama tahun 2017-2019 di Bursa Efek Indonesia. 
3. Perusahaan yang seluruh laporan keuangannya selama tahun 2017-2019 telah diaudit. Berdasarkan kriteria yang telah ditetapkan dapat dilihat pada tabel berikut, sebanyak 26 perusahaan telah ditetapkan dari total 47 perusahaan yang tercatat pada Bursa Efek Indonesia.

\begin{tabular}{lc}
\hline \multicolumn{1}{c}{ Keterangan } & Sampel \\
\hline Populasi Perusahaan & 47 \\
\hline Perusahaan yang tidak tercatat dalam Bursa Efek Indonesia & $(1)$ \\
\hline $\begin{array}{l}\text { Perusahaan yang tidak melaporkan laporan keuangannya secara } \\
\text { berturut dan diaudit }\end{array}$ & $(20)$ \\
\hline Sampel Perusahaan & $\mathbf{2 6}$ \\
\hline
\end{tabular}

Sumber: Diolah oleh peneliti

\section{Teknik Analisis Data}

Teknik analisis data yang digunakan dalam penelitian ini adalah metode analisis Partial Least Square (PLS) dimana analisis PLS merupakan suatu metode analisis yang tidak didasarkan pada banyak asumsi atau syarat serta dapat menangani banyak variabel sekaligus sekalipun terdapat multikolineritas dalam variabel-variabel tersebut (Syahrir, Yulinda, \& Yusuf, 2020). Sebelum melakukan pengujian perlu dilakukan beberapa tahapan, sebagai berikut:

1. Menghitung Free Cash Flow dengan menggunakan rumus dari Brigham dan Houston pada perusahaan jasa transportasi tahun 2017-2019.

2. Menghitung Financial Leverage setiap perusahaan jasa transportasi tahun 20172019.

3. Menghitung Earning Management setiap perusahaan jasa transportasi tahun 20172019 dengan mengidentifikasi discretionary accrual (DA).

4. Menghitung Good Corporate Govarnance setiap perusahaan jasa transportasi tahun 2017-2019 dengan metode indeks governance.

Setelah melakukan beberapa tahapan diatas, dapat dilakukan analisis data menggunakan uji outer model, uji inner model, dan uji hipotesis pada setiap hipotesis yang akan diuji pada penelitian ini.

\section{Outer Model}

Hair mengatakan bahwa model pengukuran atau Outer Model merupakan sebuah konstruksi yang menampilkan hubungan antara konstruksi dengan variabel indikator digunakan untuk menentukan bagaimana konstruksi (variabel laten) diukur (Hair Jr, Hult, Ringle, \& Sarstedt, 2021). Uji ini dapat dibagi menjadi 3 kriteria yaitu:

a. Convergent Validity

Hair mengatakan Convergent Validity merupakan perhitungan sejauh mana suatu pengukuran yang berkorelasi secara positif antara ukuran alternatif dari konstruksi yang sama. Suatu indikator dikatakan indikator yang signifikan dalam pengukuran variabel laten bila nilai standardize loading factor diatas 0,7. Selain itu Convergent Validity dikatakan telah terpenuhi bila nilai AVE lebih besar dari 0,5 (Hair Jr et al., 2021). 


\section{b. Discriminant Validity}

Hair mengatakan Discriminant Validity merupakan perhitungan sejauh mana suatu konstruksi benar-benar berbeda dengan konstruksi lainnya menurut standar empiris. Validitas diskriminan dapat dinilai berdasarkan cross loading pengukuran dengan konstruksi. Penentuan evaluasi dapat dilihat dari nilai cross loading dari setiap indikator, jika korelasi antara variabel laten dengan indikatornya memiliki nilai lebih tinggi dari pada korelasi antara variabel laten dengan indikator lainnya maka variabel laten tersebut tidak perlu dikeluarkan dari model karena dapat mengukur indikatornya dengan lebih baik (Hair Jr et al., 2021).

c. Reliability

Rachman mengatakan dalam Reliability dapat diukur dengan dua cara yaitu Composite Reliability dan Cronbach Alpha dari blok indikator yang mengukur konstruksi. Suatu konstruksi dikatakan reliabel bila nilai Composite Reliability dan Cronbach Alpha diatas 0,7 maka konstruksi tersebut memiliki relaabilitas yang tinggi (Rachman \& Marsono, 2014).

\section{Inner Model}

Hair menyatakan bahwa model struktural atau Inner Model akan menampilkan hubungan atau jalur antar konstruksi dimana teori ini akan menunjukan bagaimana variabel laten terkait satu sama lain. Kriteria yang digunakan dalam penelitian ini adalah R-Square.

\section{a. $\mathrm{R}$-Square $\left(\mathrm{R}^{2}\right)$}

Absari mengatakan bahwa $\mathrm{R}^{2}$ digunakan untuk melihat besarnya pengaruh variabel laten eksogen terhadap variabel laten endogen. Kriteria batasan nilai $\mathrm{R}^{2}$ dapat dibagi menjadi 3 klasifikasi, yaitu 0,67 (substansi); 0,33 (moderat); 0,19 (lemah) (Abshari, 2017).

\section{Uji Hipotesis}

Kriteria pengujian hipotesis untuk P-Value dan T-Statistics dapat ditentukan dengan signifikansi $\alpha=0,05$ atau 5\%. Jika pengujian hipotesis dengan nilai P-Value kurang dari $\alpha=0,05$ dan nilai T-Statistics lebih besar dari signifikansi $5 \%$ yaitu 1,96 maka hipotesis dapat diterima.

\section{Hasil dan Pembahasan}

Uji Outer Model

\section{Convergent Validity}

Tabel Outer Loadings

\begin{tabular}{lcccc}
\hline & $\begin{array}{c}\text { Earning } \\
\text { Managemen } \\
t\end{array}$ & $\begin{array}{c}\text { Free Cash } \\
\text { Flow }\end{array}$ & $\begin{array}{c}\text { Financial } \\
\text { Leverage }\end{array}$ & $\begin{array}{c}\text { Good } \\
\text { Corporate } \\
\text { Governance }\end{array}$ \\
\hline $\begin{array}{l}\text { Free Cash FLow } \\
\left(\mathrm{X}_{1}\right)\end{array}$ & 1 & & \\
\hline
\end{tabular}




\begin{tabular}{lcc}
\hline Financial Leverage & 1 & \\
$\left(\mathrm{X}_{2}\right)$ & & \\
\hline Earning & 1 & 1 \\
Management $(\mathrm{Y})$ & & \\
\hline Good Corporate & & \\
Governance $\left(\mathrm{X}_{3}\right)$ & & \\
\hline
\end{tabular}

Sumber: Diolah oleh peneliti dari PLS

Tabel AVE (Average Variance Extracted)

\begin{tabular}{lc}
\hline & AVE \\
\hline Earning Management & 1 \\
\hline Free Cash Flow & 1 \\
\hline Financial Leverage Corporate & 1 \\
\hline $\begin{array}{l}\text { Good } \\
\text { Governance }\end{array}$ & 1
\end{tabular}

Sumber: Diolah oleh peneliti dari PLS

Berdasarkan tabel diatas, hasil loading factor serta AVE dalam penelitian ini adalah 1 atau 1000. Maka dapat diartikan bahwa seluruh indikator yang digunakan tidak memiliki permasalahan korelasi serta telah memenuhi validitas konvergen.

\section{Discriminant Validity}

Tabel Cross Loading

\begin{tabular}{|c|c|c|c|c|}
\hline & $\begin{array}{l}\text { Free Cash } \\
\text { Flow }\left(\mathrm{X}_{1}\right)\end{array}$ & $\begin{array}{l}\text { Financial } \\
\text { Leverage } \\
\quad\left(\mathrm{X}_{2}\right)\end{array}$ & $\begin{array}{c}\text { Earning } \\
\text { Management } \\
\text { (Y) }\end{array}$ & $\begin{array}{c}\text { Good } \\
\text { Corporate } \\
\text { Governance } \\
\left(\mathrm{X}_{3}\right)\end{array}$ \\
\hline $\begin{array}{l}\text { Free Cash } \\
\text { FLow }\left(\mathrm{X}_{1}\right)\end{array}$ & 1 & 0,108 & 0,024 & 0,077 \\
\hline $\begin{array}{c}\text { Financial } \\
\text { Leverage }\left(\mathrm{X}_{2}\right)\end{array}$ & 0,108 & 1 & $-0,150$ & 0,064 \\
\hline $\begin{array}{c}\text { Earning } \\
\text { Management } \\
\text { (Y) }\end{array}$ & 0,024 & $-0,150$ & 1 & 0,043 \\
\hline $\begin{array}{c}\text { Good Corporate } \\
\text { Governance } \\
\left(\mathrm{X}_{3}\right)\end{array}$ & 0,077 & 0,064 & 0,043 & 1 \\
\hline
\end{tabular}


dibanding korelasi antara variabel laten dengan indikator lainnya. Maka, dapat diartikan bahwa seluruh variabel laten tidak perlu dikeluarkan dari model.

\section{Reliability}

Tabel Construct Reliability dan Validity

\begin{tabular}{lcc}
\hline & $\begin{array}{c}\text { Composite } \\
\text { Reliability }\end{array}$ & $\begin{array}{c}\text { Cronbach } \\
\text { Alpha }\end{array}$ \\
\hline Earning Management & 1 & 1 \\
\hline Free Cash Flow & 1 & 1 \\
\hline Financial Leverage & 1 & 1 \\
\hline $\begin{array}{l}\text { Good Corporate } \\
\text { Governance }\end{array}$ & 1 & 1 \\
\hline
\end{tabular}

Sumber: Diolah oleh peneliti dari PLS

Berdasarkan tabel diatas, hasil composite reliability dan cronbach alpha setiap variabel adalah 1 atau 1000. Maka, dapat diartikan bahwa semua variabel laten memiliki reliability yang tinggi. Dimana hasil reliability ini yang seluruhnya bernilai 1 dikarenakan penelitian ini menggunakan data sekunder yang didapat dari laporan keuangan dalam annual report setiap perusahaan bukan menggunakan data primer seperti data kuesioner.

\section{Uji Inner Model}

\section{1. $\mathbf{R}$-Square $\left(\mathbf{R}^{2}\right)$}

2.

Tabel R-Square

\begin{tabular}{lcl}
\hline & $\begin{array}{l}\mathrm{R}- \\
\text { Square }\end{array}$ & $\begin{array}{l}\text { R-Square } \\
\text { Adjusted }\end{array}$ \\
\hline $\begin{array}{l}\text { Earning } \\
\text { Management }\end{array}$ & 0,040 & $-0,027$ \\
\hline Sumber: Diolah oleh peneliti dari PLS
\end{tabular}

Berdasarkan tabel diatas, hasil uji R-Square dalam penelitian ini sebesar 0,040 atau sebesar $4 \%$ dimana hal ini menyatakan bahwa seluruh variabel laten eksogen lemah dalam mempengaruhi variabel laten endogennya.

Uji Hipotesis

Tabel Path Coefficient

\begin{tabular}{ccccccc}
\hline $\begin{array}{c}\text { Hipotesi } \\
\text { s }\end{array}$ & Variabel & $\begin{array}{c}\text { Original Sample } \\
\text { (Koefisien } \\
\text { Regresi) }\end{array}$ & $\begin{array}{c}\text { Standart } \\
\text { Devitiatio } \\
n\end{array}$ & $\begin{array}{c}\text { T- } \\
\text { Statistics }\end{array}$ & $\begin{array}{c}\text { P- } \\
\text { Value }\end{array}$ & Keterangan \\
\hline H1 & $\begin{array}{c}\text { FCF -> } \\
\text { EM }\end{array}$ & $-0,402$ & 0,412 & 0,976 & 0,329 & $\begin{array}{c}\text { Tidak } \\
\text { Berpengaruh }\end{array}$ \\
\hline H2 & $\begin{array}{c}\text { FL -> } \\
\text { EM }\end{array}$ & $-0,152$ & 0,098 & 1.558 & 0,120 & $\begin{array}{c}\text { Tidak } \\
\text { Berpengaruh }\end{array}$ \\
\hline $\mathrm{H} 3$ & $\begin{array}{c}\text { GCG*FC } \\
\text { F }->\text { EM }\end{array}$ & 0,545 & 0,475 & 1.147 & 0,252 & $\begin{array}{c}\text { Tidak } \\
\text { Memoderasi }\end{array}$ \\
\hline
\end{tabular}




\begin{tabular}{ccccccc}
\hline H4 & $\begin{array}{c}\text { GCG*FL } \\
\text {-> EM }\end{array}$ & $-0,071$ & 0,267 & 0,266 & 0,791 & $\begin{array}{c}\text { Tidak } \\
\text { Memoderasi }\end{array}$ \\
\hline
\end{tabular}

Sumber: Diolah oleh peneliti dari PLS

Berdasarkan dari uji hipotesis yang telah dilakukan menggunakan program Partial Least Square (PLS), maka dapat diperoleh hasil dari pengaruh antara variabel eksogen terhadap variabel endogen dengan variabel moderasi yaitu sebagai berikut:

a. Free Cash Flow, Dari hasil perhitungan melalui program PLS diperoleh nilai signifikan sebesar 0,976 < 1.96 sehingga dapat disimpulkan bahwa Free Cash Flow tidak berpengaruh secara signifikan terhadap Earning Management. Hipotesis $1\left(\mathrm{H}_{1}\right)$ dalam penelitian ini tidak diterima.

b. Financial Leverage, Dari hasil perhitungan melalui program PLS diperoleh nilai signifikan sebesar 1,558 < 1.96 sehingga dapat disimpulkan bahwa Financial Leverage tidak berpengaruh secara signifikan terhadap Earning Management. Hipotesis $2\left(\mathrm{H}_{2}\right)$ dalam penelitian ini tidak diterima.

c. Good Corporate Governane sebagai moderasi hubungan Free Cash Flow dengan Earning Management, Dari hasil perhitungan melalui program PLS diperoleh nilai signifikan sebesar 1,147 < 1.96 sehingga dapat disimpulkan bahwa Good Corporate Governance tidak dapat memoderasi hubungan antara Free Cash Flow terhadap Earning Management. Hipotesis $3\left(\mathrm{H}_{3}\right)$ dalam penelitian ini tidak diterima.

d. Good Corporate Governane sebagai moderasi hubungan Financial Leverage dengan Earning Management, Dari hasil perhitungan melalui program PLS diperoleh nilai signifikan sebesar 0,266 < 1.96 sehingga dapat disimpulkan bahwa Good Corporate Governance tidak dapat memoderasi hubungan antara Free Cash Flow terhadap Earning Management. Hipotesis $4\left(\mathrm{H}_{4}\right)$ dalam penelitian ini tidak diterima.

\section{Pembahasan}

\section{Pengaruh Free Cash Flow Terhadap Earning Management}

Berdasarkan hasil dari uji hipotesis variabel free cash flow memiliki nilai signifikan sebesar 0,976 < 1.96 dapat disimpulkan bahwa variabel free cash flow tidak berpengaruh secara signifikan terhadap earning management. Penelitian ini didukung dengan penelitian yang dilakukan oleh (Herlambang et al., 2017) yang menyatakan bahwa free cash flow berpengaruh negatif dan tidak signifikan terhadap manajemen laba, tetapi penelitian ini bertentangan dengan penelitian yang dilakukan oleh Setiawan (2019). Hasil penelitian menunjukan bahwa perusahaan dengan nilai free cash flow tinggi ataupun rendah tidak menjamin perusahaan akan melakukan earning management. Dimana hal ini dapat disimpulkan bahwa free cash flow yang tinggi dapat membatasi terjadinya earning management. Dikarenakan free cash flow dapat menjadi nilai penting untuk meningkatkan nilai perusahaan, sehingga fokus manajer adalah untuk semakin meningkatkan free cash flow. Dalam hal tersebut, para investor yang merupakan pemilik perusahaan sementara akan lebih terfokuskan terhadap nilai pada free cash flow dalam perusahaan, sehingga perusahaan dapat meningkatkan harga sahamnya tanpa melakukan 
earning management karena para investor akan melihat kemampuan perusahaan dalam membagikan deviden akibat terdapat kelebihan kas. Maka, Hipotesis $1\left(\mathrm{H}_{1}\right)$ dalam penelitian ini yaitu free cash flow berpengaruh terhadap earning management tidak diterima.

\section{Pengaruh Financial Leverage Terhadap Earning Management}

Berdasarkan hasil dari uji hipotesis variabel financial leverage memiliki nilai signifikan sebesar 1,558 < 1.96 dapat disimpulkan bahwa variabel financial levarage tidak berpengaruh secara signifikan terhadap earning management. Penelitian ini didukung dengan penelitian yang dilakukan oleh (Setiawati et al., 2019) yang menyatakan bahwa leverage tidak berpengaruh signifikan terhadap manajemen laba akrual, namun penelitian ini bertentangan dengan penelitian yang dilakukan oleh (Herlambang et al., 2017). Hasil penelitian menunjukan bahwa perusahaan dengan nilai leverage baik tinggi maupun rendah tidak menjamin perusahaan tersebut melakukan earning management. Hal ini menjelaskan bahwa perusahaan dengan hutang yang tinggi tidak menjadikan alasan perusahaan untuk melakukan earning management, dikarenakan perusahaan dengan leverage tinggi akibat total hutang masih harus memikirkan resiko tidak mampu memenuhi kewajibannya membayar hutang. Maka, Hipotesis $2\left(\mathrm{H}_{2}\right)$ dalam penelitian ini yaitu financial leverage berpengaruh terhadap earning management tidak diterima.

\section{Pengaruh Good Corporate Governance Sebagai Variabel Moderasi Terhadap Hubungan Antara Free Cash Flow Dengan Earning Management}

Berdasarkan hasil dari uji hipotesis variabel free cash flow dengan good corporate governance memiliki nilai signifikan sebesar 1,147 $<1.96$ dapat disimpulkan bahwa variabel good corporate governance tidak dapat memoderasi hubungan antara free cash flow terhadap earning management. Dimana penelitian ini didukung dengan penelitian oleh Herlambang (2017); Setiawati, dkk (2019); serta Widyanigrum, dkk (2017) yang menyatakan bahwa good corporate governance tidak dapat memoderasi hubungan antara free cash flow terhadap earning management. Hal ini menjelaskan bahwa good corporate governance dalam hubungan antara free cash flow terhadap earning management adalah bukan moderator. Maka, Hipotesis $3\left(\mathrm{H}_{3}\right)$ dalam penelitian ini yaitu good corporate governance dapat memoderasi hubungan antara free cash flow terhadap earning management tidak diterima.

\section{Pengaruh Good Corporate Governance Sebagai Variabel Moderasi Terhadap Hubungan Antara Financial Leverage Dengan Earning Management}

Berdasarkan hasil dari uji hipotesis variabel financial leverage dengan good corporate governance memiliki nilai signifikan sebesar 0,266 < 1.96 dapat disimpulkan bahwa variabel good corporate governance tidak dapat memoderasi hubungan antara financial leverage terhadap earning management. Dimana penelitian ini didukung dengan penelitian oleh (Setiawan, 2019) dan Widyanigrum, dkk (2017) yang menyatakan bahwa good corporate governance tidak dapat memoderasi hubungan antara financial 
leverage terhadap earning management, namun kondisi ini bertentangan dengan penelitian (Herlambang et al., 2017). Hal ini menjelaskan bahwa good corporate governance dalam hubungan antara financial leverage terhadap earning management adalah bukan moderator. Maka, Hipotesis $4\left(\mathrm{H}_{4}\right)$ dalam penelitian ini yaitu good corporate governance dapat memoderasi hubungan antara financial leverage terhadap earning management tidak diterima.

\section{Kesimpulan}

Dari hasil analisis serta pembahasan terkait penelitian yang telah dilakukan dengan metode sampling terhadap perusahaan jasa transportasi yang terdaftar di Bursa Efek Indonesia tahun 2017-2019 dapat ditarik kesimpulan bahwa hasil dari penelitian menyatakan bahwa free cash flow tidak berpengaruh terhadap earning management. Sehingga tinggi rendahnya free cash flow pada suatu perusahaan tidak dapat menjadi alasan bagi manajer untuk melakukan earning management. Hal tersebut dikarenakan para investor akan terfokuskan dengan nilai dari free cash flow setiap perusahaan. Hasil dari penelitian menyatakan bahwa financial leverage tidak berpengaruh terhadap earning management. Sehingga besar kecilnya hutang dalam suatu perusahaan tidak dapat menjadi alasan bagi perusahaan untuk melakukan perpindahan aset ataupun pengurangan aset dari periode sebelum ke periode sekarang untuk menutupi resiko tidak mampu melaksanakan kewajibannya untuk membayar hutang. Hasil dari penelitian menyatakan bahwa good corporate governance tidak dapat memoderasi hubungan antara free cash flow terhadap earning management. Sehingga dalam penelitian ini good corporate governance merupakan bukan moderator dalam hubungan antara free cash flow terhadap earning management. Hasil dari penelitian menyatakan bahwa good corporate governance tidak dapat memoderasi hubungan antara financial leverage terhadap earning management. Sehingga dalam penelitian ini good corporate governance merupakan bukan moderator dalam hubungan antara financial leverage terhadap earning management. 


\section{BIBLIOGRAFI}

Abshari, Hana. (2017). Moderating Structural Equation Modeling Dengan Partial Least Square Pada Persepsi Kinerja Terhadap Remunerasi Dosen Di Lingkungan Fmipa Its. Institut Teknologi Sepuluh Nopember. Google Scholar.

Agustia, Dian. (2013). Pengaruh faktor good corporate governance, free cash flow, dan leverage terhadap manajemen laba. Jurnal Akuntansi Dan Keuangan, 15(1), 27-42. Google Scholar

Fahmi, Irham. (2011). Analisis laporan keuangan. Bandung: alfabeta. Google Scholar.

Hair Jr, Joseph F., Hult, G. Tomas M., Ringle, Christian M., \& Sarstedt, Marko. (2021). A primer on partial least squares structural equation modeling (PLS-SEM). Sage publications. Google Scholar

Herlambang, Akbar Roy, Halim, Edyanus H., \& Haryetti, Haryetti. (2017). Analisis pengaruh free cash flow dan financial leverage terhadap manajemen laba dengan good corporate governance sebagai variabel moderasi. Riau University. Google Scholar

Irfani, Agus S. (2020). Manajemen Keuangan dan Bisnis; Teori dan Aplikasi. Gramedia Pustaka Utama. Google Scholar

Nugroho, Paskah Ika. (2020). Pengaruh Good Corporate Governance Terhadap Manajemen Laba. Jurnal Akuntansi Profesi, 11(2), 243-255. Google Scholar

Rachman, Feri, \& Marsono, Marsono. (2014). Analisis Pengaruh Intellectual Capital terhadap Kinerja Keuangan dan Nilai Pasar Perusahaan (Studi pada Perusahaan yang Terdaftar di Bursa Efek Indonesia Tahun 2008-2012). Diponegoro Journal of Accounting, 3(1), 92-104. Google Scholar

Setiawan, Billy Christian. (2019). Pengaruh Ukuran perusahaan, Leverage ratio, Arus kas bebas terhadap manajemen laba pada perusahaan perdagangan eceran yang terdaftar di BEI tahun 2014-2017. Universitas Widya Kartika. Google Scholar

Setiawati, Erma, Mujiyati, Mujiyati, \& Rosit, Erma Marga. (2019). Pengaruh Free cash flow Dan Leverage Terhadap Manajemen Laba Dengan Good Corporate Governance Sebagai Variabel Moderasi. Akuntabilitas, 13(1), 69-82. Google Scholar

Sulistyanto, Sri. (2008). Manajemen Laba (Teori \& Model Empiris). Grasindo. Google Scholar

Syahrir, Danial, Yulinda, Eni, \& Yusuf, Muhammad. (2020). Aplikasi Metode SEM-PLS dalam Pengelolaan Sumberdaya Pesisir dan Lautan. PT Penerbit IPB Press. Google Scholar 
Tjindrawati Kosasih, Melvie Paramitha

Widyaningrum, Rahma, Amboningtyas, Dheasey, \& Fathoni, Azis. (2018). The Effect Of Free Cash Flow, Profitability, And Leverage To Earnings Managemet With Good Corporate Governance As A Moderating Variable (Empirical Study on Banking Companies Listed on the Indonesian Stock Exchange For The Period 20122016). Journal of Management, 4(4). Google Scholar

Yunila, Felismina, \& Aryati, Titik. (2018). Pengaruh Perencanaan Pajak dan Pajak Tangguhan Terhadap Manajemen Laba dengan Kualitas Audit sebagai variabel moderasi. Prosiding Seminar Nasional Cendekiawan, 1021-1027. Google Scholar

First publication right:

Jurnal Syntax Fusion: Jurnal Nasional Indonesia

This article is licensed under:

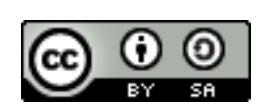

